\title{
Polpa cítrica em rações para cordeiros em confinamento: características da carcaça e qualidade da carne ${ }^{1}$
}

\section{Gustavo Henrique Rodrigues ${ }^{2}$, Ivanete Susin ${ }^{3}$, Alexandre Vaz Pires ${ }^{3}$, Clayton Quirino Mendes ${ }^{2}$, Fumi Shibata Urano ${ }^{2}$, Carmen Josefina Contreras Castillo 4}

\footnotetext{
1 Projeto parcialmente financiado pela FAPESP.

2 Pós-graduação em Ciência Animal e Pastagens - ESALQ/USP - Piracicaba, SP

${ }^{3}$ Departamento de Zootecnia - ESALQ/USP - Piracicaba, SP. Bolsista do CNPq.

${ }^{4}$ Departamento de Agroindústria, Alimentos e Nutrição - ESALQ/USP - Piracicaba, SP.
}

RESUMO - Objetivou-se avaliar os efeitos do fornecimento de polpa cítrica na dieta sobre as características de carcaça e a qualidade da carne de cordeiros em confinamento. Utilizaram-se 32 cordeiros Santa Inês distribuídos em delineamento de blocos completos casualizados com quatro tratamentos e oito repetições, os quais foram definidos pelo peso e pela idade dos animais no início do experimento de desempenho. Os animais foram alimentados com rações contendo 90\% de concentrado (milho moído e/ou polpa cítrica, farelo de soja e minerais) e 10\% de feno de coastcross (Cynodon spp). A polpa cítrica foi adicionada nos níveis 23,7; 46,1 e 68,4\% da MS em substituição a 33, 67 e 100\% do milho. Ao atingirem $33 \mathrm{~kg}$ de peso corporal médio, os cordeiros foram abatidos para avaliação dos rendimentos de carcaça quente e fria, da perda por resfriamento, da espessura de gordura de cobertura, da área de olho-de-lombo, dos rendimentos de cortes e da proporção músculo:gordura:osso, além da capacidade de retenção de água, da cor, da perda de peso por cozimento e do pH da carne. As características de carcaça não foram alteradas pela substituição parcial ou total do milho por polpa cítrica. Entretanto, a substituição total do milho por polpa cítrica reduziu em 12,4\% o teor de gordura na carcaça.

Palavras-chave: ovinos, pectina, Santa Inês, subprodutos

\section{Citrus pulp in diets for feedlot lambs: carcass characteristics and meat quality}

\begin{abstract}
The objective of this trial was to determine the effects of feeding diets containing citrus pulp on carcass characteristics and meat quality of feedlot lambs. Thirty-two Santa Ines lambs were distributed in a complete randomized block design according to body weight and age at the beginning of the performance trial. Lambs were fed diets containing $90 \%$ concentrate (corn and/or citrus pulp, soybean meal and minerals) and 10\% coastcross hay (Cynodon spp). Citrus pulp was added at levels $23.7,46.1$ and $68.4 \%$ in the DM, replacing corn by 33, 67 or $100 \%$. When lambs reached $33 \mathrm{~kg}$ of BW, they were slaughtered to determine dressing percentage, cold carcass yield, chilling loss, backfat thickness, loin eye area, cut yields and proportion of muscle, fat and bone. In addition, water holding capacity, color, cooking loss and $\mathrm{pH}$ were determined. Carcass characteristics were not altered by feeding citrus pulp to the lambs. However, the total replacement of corn by citrus pulp decreased carcass fat content by $12.4 \%$.
\end{abstract}

Key Words: by-products, pectin, Santa Ines, sheep

\section{Introdução}

O consumo de carne ovina pelos brasileiros é menor que o das carnes bovina, suína, de aves e de peixes. Contudo, nos grandes centros urbanos, principalmente na Região Sudeste, tem-se observado aumento no consumo de carne ovina e perspectivas de comercialização promissoras. Como conseqüência dessa demanda, plantas frigoríficas têm sido instaladas ou adaptadas para o abate de ovinos.
A aceitabilidade da carne ovina pelo consumidor, além do grupo genético, é influenciada pelo tipo de alimentação do animal, pela idade ao abate, pelo armazenamento da carcaça fria (Sañudo et al., 1998) e pelos atributos de qualidade da carne.

Aliada ao aumento da produção, a manipulação da qualidade nutricional e sensorial da carne por meio da nutrição animal tem ganhado importância nos últimos anos, tornando possível obter produtos cárneos diferenciados 
(Lynch \& Kerry, 2000). Assim, a estratégia de confinamento é uma forma de atender às duas principais partes da cadeia produtiva (produtor e consumidor), ou seja, encurta o ciclo de produção e coloca no mercado carcaças de animais mais precoces e carne ovina de qualidade.

A polpa cítrica desidratada (PC), subproduto da indústria citrícola, pode ser utilizada em rações para ruminantes como ingrediente de alta densidade energética para animais em crescimento e lactação e tem pouco ou nenhum efeito negativo na fermentação ruminal em comparação a alimentos ricos em amido (Bampidis \& Robinson, 2006). No entanto, a substituição de ingredientes tradicionais, como o milho, por subprodutos como a polpa cítrica, pode alterar a composição e a qualidade da carne ovina, mesmo que o desempenho seja satisfatório (Vasta et al., 2007).

A utilização de polpa cítrica na produção de carne ovina pode ocasionar mudanças em algumas características de qualidade da carne, como a cor (Caparra et al., 2007) e a maciez (Scerra et al., 2001). A polpa de beterraba, outro subproduto rico em pectina, como a polpa cítrica, influencia a coloração, o pH final e a perda de peso por cocção da carne de cordeiros (Olfaz et al., 2005).

Este estudo foi realizado com o objetivo de avaliar o efeito da inclusão de polpa cítrica na ração sobre as características de carcaça e a qualidade da carne de cordeiros da raça Santa Inês confinados.

\section{Material e Métodos}

O experimento foi realizado no Sistema Intensivo de Produção de Ovinos e Caprinos, do Departamento de Zootecnia da ESALQ/USP.

Avaliaram-se quatro rações para cordeiros Santa Inês recém-desmamados com peso corporal de $18 \pm 0,6 \mathrm{~kg}$ e $73 \pm 1$ dias de idade no início do experimento (Rodrigues et al., 2008). As rações (Tabela 1) foram formuladas para serem isonitrogenadas (16\% PB) e foram compostas de $10 \%$ de volumoso (feno de coastcross, Cynodon spp) e $90 \%$ de concentrado na matéria seca (MS). A polpa cítrica foi adicionada às rações nas proporções de 23,7; 46,1 e $68,4 \%$ da MS, correspondentes a 0, 33, 67 e $100 \%$ de substituição do milho.

Ao final do período experimental de desempenho, oito animais de cada tratamento foram abatidos assim que atingiram peso corporal médio de $33 \mathrm{~kg}$. Os animais foram pesados após jejum de sólidos de 16 horas e, em seguida, foram abatidos segundo as normas descritas no Regulamento da Inspeção Industrial e Sanitária de Produtos de Origem Animal-RIISPOA (BRASIL, 1997). Posteriormente
Tabela 1 - Composição das rações experimentais (\% MS)

\begin{tabular}{|c|c|c|c|c|}
\hline \multirow[t]{2}{*}{ Ingrediente } & \multicolumn{4}{|c|}{$\begin{array}{l}\text { Nível de substituição do } \\
\text { milho por polpa cítrica (\%) }\end{array}$} \\
\hline & 0 & 33 & 67 & 100 \\
\hline Feno de coastcross & 10,0 & 10,0 & 10,0 & 10,0 \\
\hline Milho moído & 70,4 & 47,2 & 23,4 & - \\
\hline Polpa cítrica moída & - & 23,7 & 46,1 & 68,4 \\
\hline Farelo soja & 16,0 & 17,0 & 17,9 & 18,2 \\
\hline Cloreto de amônio & 0,5 & 0,5 & 0,5 & 0,5 \\
\hline Calcário calcítico & 1,5 & - & - & - \\
\hline Monoaminofosfato & - & - & 0,5 & 1,3 \\
\hline Mistura mineral ${ }^{1}$ & 1,6 & 1,6 & 1,6 & 1,6 \\
\hline \multicolumn{5}{|l|}{ Composição química (\% MS) } \\
\hline Matéria seca & 88,8 & 89,4 & 89,9 & 91,4 \\
\hline Matéria orgânica & 91,6 & 94,0 & 92,9 & 91,7 \\
\hline Proteína bruta & 17,5 & 17,1 & 17,9 & 17,3 \\
\hline Fibra detergente neutro & 19,5 & 20,4 & 24,2 & 24,6 \\
\hline Nutrientes digestíveis totais ${ }^{2}$ & 77,8 & 78,3 & 77,4 & 74,3 \\
\hline \multicolumn{5}{|c|}{$\begin{array}{l}{ }^{1} \text { Composição: P - 7,5\%; Ca - 13,4\%; Mg - 1\%; S - 7\%; Na - 14,5\% } \\
\text { Cl - 21,8\%; Fe - } 500 \mathrm{mg} / \mathrm{kg} ; \mathrm{Cu}-300 \mathrm{mg} / \mathrm{kg} ; \mathrm{Zn}-4.600 \mathrm{mg} / \mathrm{kg} ; \mathrm{Mn} \\
1.100 \mathrm{mg} / \mathrm{kg} ; \mathrm{I}-55 \mathrm{mg} / \mathrm{kg} ; \mathrm{Co}-40 \mathrm{mg} / \mathrm{kg} ; \mathrm{Se}-30 \mathrm{mg} / \mathrm{kg} \text {. } \\
2 \text { Nutrientes digestíveis totais foram calculados de acordo com Lofgreen } \\
\text { (1953), assumindo que a digestibilidade da matéria orgânica é igual ao } \\
\text { NDT. }\end{array}$} \\
\hline
\end{tabular}

ao abate, foram pesados as vísceras, a cabeça, os pés e o couro de cada animal. As carcaças foram seccionadas longitudinalmente em duas meias-carcaças e pesadas individualmente para obtenção do peso de carcaça quente. Depois de 24 horas em câmara fria de resfriamento a $4^{\circ} \mathrm{C}$, obteve-se o peso da carcaça fria, que foi utilizado para determinação dos rendimentos de carcaça quente (RCQ) e de carcaça fria (RCF) e da perda por resfriamento (PR).

A meia-carcaça direita foi utilizada para medida de espessura de gordura (EG) e da área de olho-de-lombo (AOL). A medida da espessura de gordura foi realizada entre a $12^{\underline{a}}$ e $13^{\underline{a}}$ costelas da parte posterior da meiacarcaça por meio de um paquímetro graduado em milímetros. A área de olho-de-lombo foi desenhada no músculo exposto Logissimus dorsi utilizando-se papel vegetal e, posteriormente, calculada em planímetro graduado em $\mathrm{cm}^{2}$. A meia-carcaça fria direita foi separada em três cortes principais: dianteiro (pescoço, membro anterior e cinco costelas), traseiro (perna, garupa, lombo separado do dianteiro entre a quinta e sexta costelas) e costilhar (costelas, a partir da sexta, separadas do traseiro a $2 \mathrm{~cm}$ da coluna vertebral, mais os músculos abdominais), de modo que cada corte foi pesado e o resultado foi expresso em porcentagem da meia-carcaça. Posteriormente, em cada corte, realizaram-se a separação física e a pesagem dos componentes ossos, gordura e músculos, também expressos em porcentagem.

As leituras de $\mathrm{pH}$ e temperatura foram realizadas às 1 , 3, 6, 9 e 24 horas post mortem, no músculo Longissimus 
dorsi, com auxílio de peagâmetro portátil com eletrodo de penetração da marca Digmed, modelo DM 20, com resolução de 0,01 unidades de $\mathrm{pH}$. O aparelho foi calibrado com solução tampão de pH 4,00 e pH 6,86, de modo que a calibragem foi realizada a cada cinco leituras. A limpeza do eletrodo foi feita com detergente neutro e água destilada no final das leituras. Para a inserção do eletrodo, o músculo foi seccionado com a ponta de uma faca. A cada leitura, foram realizadas três medidas de pH e sua média utilizada na análise estatística.

Para a análise da cor, foi utilizado o colorímetro Minolta Chroma Meter CR 300, calibrado para um padrão. O sistema de avaliação usado foi CIELAB, no qual L* corresponde à intensidade de luminosidade, $\mathrm{a}^{*}$, à intensidade de vermelho e b*, à de amarelo, e com as seguintes características: área de medição $8 \mathrm{~mm}$ de diâmetro, ângulo de observação $10^{\circ}$, iluminante D65 com componente especular incluído. Após a exposição das amostras ao ar atmosférico por 30 minutos, realizaram-se três leituras em pontos distintos no músculo Longissimus dorsi e as médias foram utilizadas para a análise estatística.

As mesmas amostras utilizadas para a análise de cor foram processadas em forma de bife medindo $2,5 \mathrm{~cm}$ de espessura para a análise de perda de peso por cozimento (PPC). As amostras foram identificadas, pesadas em balança semi-analítica (precisão de $\pm 0,01 \mathrm{~g}$ ), acondicionadas em embalagens “cook-in” (Cryovac), seladas e levadas para cozimento em banho-maria da marca Equilabor com capacidade de $10 \mathrm{~L}$ previamente estabilizado a $90^{\circ} \mathrm{C}$ até que a temperatura da carne atingisse $75^{\circ} \mathrm{C}$. Para monitorar a temperatura interna, foi utilizado um termômetro digital no centro geométrico de cada amostra. Posteriormente, a amostra foi esfriada em temperatura ambiente e novamente pesada e a diferença de peso inicial e final da amostra correspondeu ao PPC, expresso em porcentagem, conforme descrito por Cañeque et al. (2004).

Para determinação da capacidade de retenção de água (CRA), foi utilizada a metodologia descrita por Nakamura \& Katoh (1985) utilizando-se $1 \mathrm{~g}$ do Longissimus dorsi cru em papel-filtro e centrífuga não refrigerada da marca IEC a $1500 \mathrm{G}$ por 4 minutos. Após a centrifugação, a amostra foi pesada e colocada em estufa a $70^{\circ} \mathrm{C}$ durante 12 horas. O valor de CRA foi determinado pela diferença entre o peso da amostra após centrifugação e o peso da amostra seca, dividida pelo peso final e expressa em porcentagem.

O delineamento experimental foi o de blocos completos casualizados com quatro tratamentos e oito repetições, no qual os blocos foram definidos previamente pelo peso e pela idade dos animais no início do experimento de desem- penho. Os dados foram analisados pelo procedimento GLM do pacote estatístico SAS (1999). As médias das tabelas foram obtidas pelo comando LSMEANS. Para as variáveis com respostas significativas, utilizaram-se o teste de polinômios ortogonais $(\mathrm{P}<0,05)$ e análise de regressão simples. A análise de $\mathrm{pH}$ foi feita como parcela subdividida no tempo (hora das medidas) pelo procedimento MIXED (SAS, 1999).

\section{Resultados e Discussão}

Para completa avaliação do sistema de produção, as características da carcaça são consideradas informações importantes, uma vez que complementam os resultados de influência da nutrição sobre o desempenho animal.

Os pesos e os rendimentos de carcaça não foram afetados $(\mathrm{P}>0,05)$ pela substituição do milho por polpa cítrica na ração, resultado observado também para a espessura de gordura e área de olho-de-lombo (Tabela 2).

A inclusão de polpa cítrica não provocou alteração $(\mathrm{P}>0,05)$ na espessura de gordura das carcaças dos cordeiros. Diferentemente deste resultado, Henrique et al. (2004) observaram redução linear dessa variável com o acréscimo de até 55\% de polpa cítrica na alimentação de bovinos confinados e atribuíram esse efeito ao menor valor energético da polpa cítrica em relação ao milho segundo o NRC (2001). Caparra et al. (2007) também verificaram diminuição na gordura subcutânea de cordeiros alimentados com $45 \%$ de polpa cítrica desidratada ao sol. Apesar de a espessura de gordura não ter refletido o teor energético da polpa cítrica neste estudo, a quantidade de gordura foi influenciada pela adição do subproduto na ração. O valor médio de espessura de gordura obtido neste trabalho foi de 1,63 mm e pode ser explicado pelo grupo genético e pelo fato de os animais serem jovens, com média 141 dias de idade ao abate. Semelhantemente, Urano et al. (2006) verificaram média de 1,5 mm para espessura de gordura em cordeiros da raça Santa Inês com idade média e peso médio ao abate de 150 dias e $37,7 \mathrm{~kg}$, respectivamente.

O rendimento de carcaça quente (RCQ) é uma informação importante, pois representa a rentabilidade da porção comestível. O valor médio de 49,87\% observado neste experimento para RCQ pode ser considerado bom para a raça Santa Inês, pois não foi verificada diferença entre os tratamentos para esta variável, concordando com os resultados relatados por Henrique et al. (1998), que não verificaram diferença neste parâmetro em bovinos em confinamento alimentados com polpa cítrica. 
Tabela 2 - Características da carcaça de cordeiros alimentados com rações contendo polpa cítrica em susbtituição ao milho

\begin{tabular}{|c|c|c|c|c|c|c|}
\hline \multirow[t]{2}{*}{ Item } & \multicolumn{4}{|c|}{ Nível de substituição do milho por polpa cítrica (\%) } & \multirow[t]{2}{*}{$\mathrm{EPM}^{1}$} & \multirow[t]{2}{*}{$\mathrm{P}^{2}$} \\
\hline & 0 & 33 & 67 & 100 & & \\
\hline Peso de abate $(\mathrm{kg})$ & 33,3 & 33,3 & 33,4 & 32,5 & 0,42 & 0,71 \\
\hline Idade de abate (dias) & 138 & 139 & 139 & 149 & 5,16 & 0,30 \\
\hline Peso da carcaça quente $(\mathrm{kg})$ & 16,5 & 16,6 & 16,8 & 16,2 & 0,30 & 0,60 \\
\hline Peso da carcaça fria (kg) & 16,3 & 16,3 & 16,4 & 15,8 & 0,30 & 0,54 \\
\hline Rendimento da carcaça quente (\%) & 49,6 & 49,7 & 50,4 & 49,8 & 0,80 & 0,80 \\
\hline Rendimento da carcaça fria (\%) & 48,8 & 49,0 & 49,1 & 48,4 & 0,78 & 0,90 \\
\hline Área de olho-de-lombo $\left(\mathrm{cm}^{2}\right)$ & 12,5 & 12,0 & 13,1 & 12,7 & 0,48 & 0,50 \\
\hline Perda por resfriamento (\%) & 1,42 & 1,52 & 2,61 & 2,88 & 0,48 & 0,09 \\
\hline Espessura de gordura (mm) & 1,5 & 1,7 & 1,9 & 1,5 & 0,19 & 0,27 \\
\hline
\end{tabular}

${ }^{1}$ Erro-padrão da média.

2 Probabilidade de haver efeito significativo $(P<0,05)$ entre os tratamentos.

A área de olho-de-lombo (AOL) é uma medida que reflete a composição cárnea da carcaça e apresentou valor médio de $12,57 \mathrm{~cm}^{2}$, não sendo influenciada pelos níveis de polpa cítrica $(\mathrm{P}>0,05)$. Notter et al. (2004), comparando o crescimento e as características de carcaça entre grupos genéticos com pesos de abate de 42,2 kg para Dorper e de 41,0 kg para Dorset, encontraram valores de AOL similares ao deste estudo, 12,1 e $12 \mathrm{~cm}^{2}$, respectivamente. Valores para AOL de $18,14 \mathrm{~cm}^{2}$ foram observados na carcaça de cordeiros da raça Santa Inês alimentados com rações de alto teor de concentrado (80\%) por Oliveira et al. (2002), porém o peso corporal de abate foi de $45 \mathrm{~kg}$ e a idade dos animais de 7 meses.

A perda por resfriamento (PR) é um parâmetro que indica a perda de peso da carcaça ocasionada pelo resfriamento. Geralmente esta variável está inversamente correlacionada à espessura de gordura. Da mesma forma que verificado por Caparra et al. (2007), que trabalharam com cordeiros da raça Merino Italiano com peso médio de abate de $30 \mathrm{~kg}$ alimentados com polpa cítrica desidratada ao sol, a inclusão de polpa cítrica neste estudo não teve efeito $(\mathrm{P}>0,05)$ sobre essa variável.

Uma ótima proporção para cada corte é aquela em que o corte atinge valorização máxima, tanto para o produtor como para o consumidor. O valor econômico difere entre cortes e a proporção de cada um é importante na avaliação da qualidade comercial da carcaça.

As porcentagens dos cortes em relação ao peso das carcaças frias não diferiram $(\mathrm{P}>0,05)$ entres as rações (Tabela 3). O valor médio do dianteiro foi 39,45\%; do traseiro $31,25 \%$; da barriga $14,42 \%$; e do lombo $13,18 \%$. Observou-se efeito quadrático $(\mathrm{P}<0,03)$ nas proporções de músculo e de gordura e na relação músculo:gordura, ou seja, houve redução na proporção de carne e aumento na de gordura até o nível de substituição de $67 \%$ do milho, o que está relacionado ao fato de que a polpa cítrica proporciona melhor padrão de fermentação ruminal em rações mistas, em comparação às fontes de amido tradicionais, como conseqüência de seu menor conteúdo de amido e da maior concentração de pectina (Van Soest, 1982).

No entanto, observaram-se declínio na proporção de gordura e aumento na proporção de carne quando o milho foi totalmente substituído por polpa cítrica, o que pode ser explicado pelo menor conteúdo de energia da polpa cítrica em relação ao milho (NRC, 2001), caracterizando sistemas de alimentação de menor valor energético. Além disso, a menor deposição de gordura na carcaça dos animais alimentados exclusivamente com polpa cítrica pode ser atribuída às diferenças na produção de ácidos graxos voláteis promovidos pela polpa cítrica durante sua fermentação no rúmen, como verificado por Caparra et al. (2007).

Os valores médios dos componentes constituintes da cor foram para o valor L (luminosidade) de 42,62, para a* (vermelho) de 14,68 e para b* (amarelo) de 7,22 e não diferiram ( $\mathrm{P}>0,05)$ entre os níveis de polpa cítrica (Tabela 4).

Bressan et al. (2001), comparando cordeiros nãocastrados da raça Santa Inês e Bergamácia abatidos com diversos pesos, constataram valores de 32,46 a 42,29 (L*), de 10,39 a 13,89 (a*) e de 6,73 a 8,15 (b*) e verificaram que, com o aumento de peso ao abate de 15 para $45 \mathrm{~kg}$, a carne dos cordeiros apresentou coloração vermelha mais escura, confirmando resultados descritos por Bonagurio et al. (2003), em pesquisa com cordeiros Santa Inês e mestiços Santa Inês $\times$ Texel abatidos com diferentes pesos de abate. Zapata et al. (2000) não encontraram diferença nos valores de L*, a* e b* de carcaças das raças Somalis Brasileira $\times$ Crioula e Santa Inês $\times$ Crioula, com valores variando de 36,67 a 37,70; 14,85 a 15,54 e 0,83 a 1,37, respectivamente. Os resultados de coloração neste trabalho indicam que a carne apresentou coloração vermelha mais brilhante em comparação a trabalhos com mesmo grupo genético (Santa Inês), no entanto, não houve efeito dos níveis de polpa cítrica na coloração vermelha, resultados que diferem dos obtidos por Caparra et al. (2007). Segundo esses autores, 
Tabela 3 - Características da carcaça de cordeiros alimentados com rações contendo polpa cítrica em susbtituição ao milho

\begin{tabular}{|c|c|c|c|c|c|c|}
\hline Item & \multicolumn{4}{|c|}{ Nível de substituição do milho por polpa cítrica (\%) } & $\mathrm{EPM}^{1}$ & $\mathrm{P}^{2}$ \\
\hline \multicolumn{7}{|l|}{ Rendimento (\%) } \\
\hline Traseiro & 31,5 & 30,4 & 31,3 & 31,9 & 0,46 & 0,16 \\
\hline Barriga & 15,0 & 14,5 & 14,6 & 13,5 & 0,39 & 0,07 \\
\hline Lombo & 13,4 & 14,2 & 12,4 & 12,7 & 0,52 & 0,11 \\
\hline Vísceras & 9,0 & 8,7 & 8,9 & 8,9 & 0,25 & 0,79 \\
\hline Cabeça & 2,1 & 2,0 & 2,1 & 2,1 & 0,05 & 0,65 \\
\hline Pés & 0,9 & 0,9 & 0,9 & 0,9 & 0,02 & 0,83 \\
\hline Couro & 3,0 & 3,2 & 3,0 & 2,8 & 0,11 & 0,11 \\
\hline \multicolumn{7}{|l|}{ Proporção, \% } \\
\hline Músculo ${ }^{3}$ & 55,5 & 53,4 & 53,0 & 56,4 & 0,88 & 0,04 \\
\hline
\end{tabular}

${ }^{1}$ Erro-padrão da média.

2 Probabilidade de haver efeito significativo $(P<0,05)$ entre os tratamentos.

$3 \hat{Y}=55,585-0,1173 X+0,0012 X^{2}\left(P<0,01 ; R^{2}=0,25\right)$.

$4 \hat{Y}=20,805+0,0618 X-0,0008 X^{2}\left(P<0,03 ; R^{2}=0,21\right)$.

$5 \hat{Y}=2,7191-0,0143 X+0,0002 X^{2}\left(P<0,01 ; R^{2}=0,24\right)$.

Tabela 4 - Capacidade de retenção de água (CRA), perda de peso por cozimento (PPC) e cor do músculo Longissimus dorsi de cordeiros alimentados com rações contendo polpa cítrica em substituição ao milho

\begin{tabular}{|c|c|c|c|c|c|c|}
\hline \multirow[t]{2}{*}{ Item } & \multicolumn{4}{|c|}{ Nível de substituição do milho por polpa cítrica (\%) } & \multirow[t]{2}{*}{$\mathrm{EPM}^{1}$} & \multirow[t]{2}{*}{$\mathrm{P}^{2}$} \\
\hline & 0 & 33 & 67 & 100 & & \\
\hline CRA (\%) & 62,5 & 60,6 & 58,5 & 61,8 & 1,24 & 0,14 \\
\hline PPC (\%) & 19,6 & 22,5 & 19,2 & 19,7 & 2,50 & 0,78 \\
\hline \multicolumn{7}{|l|}{ Cor } \\
\hline $\mathrm{L}^{*}$ & 42,1 & 42,7 & 42,7 & 43,0 & 0,51 & 0,56 \\
\hline$a^{*}$ & 15,1 & 14,3 & 14,7 & 14,7 & 0,48 & 0,65 \\
\hline$b^{*}$ & 7,7 & 7,0 & 7,1 & 7,1 & 0,39 & 0,58 \\
\hline
\end{tabular}

${ }^{1}$ Erro-padrão da média.

2 Probabilidade de haver efeito significativo $(P<0,05)$ entre os tratamentos.

cordeiros da raça Merino italiano alimentados com polpa cítrica desidratada ao sol na proporção de 0 e $30 \%$ na ração apresentaram carne com coloração mais avermelhada que a daqueles alimentados com $45 \%$, contudo não foi verificada diferença nos valores $\mathrm{L}^{*}$ e $\mathrm{b}^{*}$.

Não houve diferença $(\mathrm{P}>0,05)$ entre os níveis de polpa cítrica para a perda de peso por cozimento (PPC), o que também está de acordo com os resultados encontrados por Caparra et al. (2007), que não notaram efeito da polpa cítrica nesta variável. Bonagurio et al. (2003) encontraram valores de PPC para o grupo genético Santa Inês variando de $37,1 \%$ a 35,8\% e para o cruzamento Texel e Santa Inês, de 40,5 a 35,5\% de PPC. Bressan et al. (2001), em estudo com cordeiros das raças Santa Inês e Bergamácia, encontraram valores que variaram de 27,2 a 33,1\% de PPC, sendo que Souza et al. (2004) verificaram valores de 33,3 a 37,9\% para cordeiros Santa Inês $\times$ Ile de France e Santa Inês $\times$ Bergamácia, respectivamente, os quais foram considerados elevados se comparados à variação de 19,2 a 22,5\% de PPC encontrada neste estudo, provavelmente em razão da metodologia utilizada pelos autores.

Hopkins \& Fogarty (1998) estudaram seis genótipos e verificaram diferença entre raças ao avaliarem PPC, de modo que os cruzamentos Texel $\times$ Merino e Poll Dorset $\times$ Merino apresentaram maior PPC (33,8 e 33,5\%, respectivamente) em relação a cordeiros resultantes do cruzamento Border Leicester $\times$ Merino (31,5\%). A explicação dada pelos autores é de que os animais cruzados com Texel podem ter perdido mais água por terem depositado menos gordura em suas carcaças, o que não ocorreu neste 
estudo nos animais recebendo rações contendo exclusivamente polpa cítrica.

A capacidade de retenção de água (CRA) é um atributo importante pois afeta a aparência da carne antes e durante o cozimento e a suculência durante a mastigação e em carnes destinadas à elaboração de embutidos, que apresentam reduzido tamanho de partícula (Lawrie, 2005). Esta característica neste estudo não foi influenciada ( $\mathrm{P}>0,05)$ pelos níveis de polpa cítrica e apresentou valor médio de 60,1\%. Entretanto, Zeola et al. (2002), avaliando a influência da alimentação nos parâmetros qualitativos da carne de cordeiros Morada Nova, verificaram que os níveis de concentrado (30, 45 e 60\%) na ração influenciaram a capacidade de retenção de água, com valores de 51,6; 52,2 e 54,6\%, respectivamente. Entretanto, Santos-Silva et al. (2002) verificaram maiores valores de capacidade de retenção de água em cordeiros Merino Branco e cruzas Ile de France $\times$ Merino Branco mantidos em pastejo, em comparação a animais confinados ou sob suplementação a pasto.
$\mathrm{O} \mathrm{pH}$ final (pHf) da carne, a partir do qual o rigor mortis é estabelecido, tem sido atribuído ao estresse anterior ao abate, que reduz o nível de glicogênio muscular e aumenta o $\mathrm{pH}$ da carne post mortem (Apple et al., 1995).

Não se observou diferença $(\mathrm{P}>0,05)$ entre os níveis de polpa cítrica para a variável pHf, cujos valores variaram de 6,67 a 6,83 na primeira hora após o abate e de 5,63 a 5,56 nas 24 horas após o abate (Tabela 5). No entanto, Bressan et al. (2001) observaram que, apesar de os valores de pHf serem similares entre os grupos de animais com diferentes pesos, a velocidade de redução do pH é mais rápida nos grupos de cordeiros com 35 e 45 kg em comparação aos grupos de 15 e $25 \mathrm{~kg}$, supostamente em virtude da maior quantidade de gordura subcutânea encontrada nos cordeiros mais pesados, que atuou como isolante térmico acelerando a glicólise. Neste experimento, a menor proporção de gordura na carcaça quando o milho foi totalmente substituído por polpa cítrica não influenciou o pH inicial e final das carcaças dos cordeiros, o que confirma os resultados encontrados por Caparra et al. (2007).

Tabela 5 - Valores médios de pH 1, 3, 6, 9 e 24 horas após o abate de cordeiros alimentados com rações contendo polpa cítrica em susbtituição ao milho

\begin{tabular}{|c|c|c|c|c|c|c|}
\hline \multirow[t]{2}{*}{ Item } & \multicolumn{4}{|c|}{ Nível de substituição do milho por polpa cítrica (\%) } & \multirow[t]{2}{*}{$\mathrm{EPM}^{1}$} & \multirow[t]{2}{*}{$\mathrm{P}^{2}$} \\
\hline & 0 & 33 & 67 & 100 & & \\
\hline pH 1 hora & 6,67 & 6,68 & 6,81 & 6,83 & 0,05 & 0,12 \\
\hline $\mathrm{pH} 3$ horas & 6,37 & 6,42 & 6,47 & 6,54 & 0,07 & 0,27 \\
\hline pH 6 horas & 6,17 & 6,09 & 6,13 & 6,30 & 0,07 & 0,26 \\
\hline pH 9 horas & 5,94 & 5,88 & 5,84 & 5,88 & 0,05 & 0,53 \\
\hline pH 24 horas & 5,63 & 5,59 & 5,61 & 5,61 & 0,03 & 0,56 \\
\hline
\end{tabular}

${ }^{1}$ Erro-padrão da média.

2 Probabilidade de haver efeito significativo $(P<0,05)$ entre os tratamentos.

\section{Conclusões}

A substituição parcial ou total do milho por polpa cítrica na dieta não influencia as características de carcaça de cordeiros em confinamento. Entretanto, a substituição total do milho por polpa cítrica reduz em $12,4 \%$ o teor de gordura na carcaça.

\section{Agradecimento}

À médica veterinária Marcia Mayumi Harada Haguiwara, do Instituto de Tecnologia de Alimentos (ITAL), pelo auxílio no abate dos animais e nas análises das carcaças.

\section{Literatura Citada}

APPLE, J.K.; DIKEMAN, M.E.; MINTON, J.E. et al. Effects of restrain and isolation stress and epidural blockade on endocrine and blood metabolite status, muscle glycogen metabolism, and indice of dark-cutting Longissimus muscle of sheep. Journal of Animal Science, v.73, p.2295-2307, 1995.

BAMPIDIS, V.A.; ROBINSON, P.H. Citrus by-products as ruminant feeds: a review. Animal Feed Science and Technology, v.128, p.175-217, 2006.

BONAGURIO, S.; PÉREZ, J.R.O.; FURUSHO GARCIA, I.F. et al. Qualidade da carne de cordeiros Santa Inês puros e mestiços com Texel abatidos com diferentes pesos. Revista Brasileira de Zootecnia, v.32, n.6, p.1981-1991, 2003 (supl.2).

BRASIL. Ministério da Agricultura. Decreto lei no 2.244, 5 jun., 1997. Regulamento da inspeção industrial e sanitária de produtos de origem animal. Brasília: 1997. 204p.

BRESSAN, M.C.; PRADO, O.V.; PÉREZ, J.R.O. et al. Efeito do peso ao abate de cordeiros Santa Inês e Bergamácia sobre as 
características físico-químicas da carne. Ciência e Tecnologia de Alimentos, v.21, n.3, p.293-303, 2001.

CAÑEQUE, V.; PEREZ, C.; VELASCO, S. et al. Carcass and meat quality of light lambs using principal component analysis. Meat Science, v.67, n.4, p.595-605, 2004.

CAPARRA, P.; FOTI, F.; SCERRA, M. et al. Solar-dried citrus pulp as an alternative energy source in lamb diets: effects on growth an carcass and meat quality. Small Ruminant Research, v.40, n.3, p.303-311, 2007.

HENRIQUE, W.; LEME, P.R.; LANNA, D.P.D. et al. Substituição de amido por pectina em dietas com diferentes níveis de concentrado. 1. Desempenho animal e características de carcaça. Revista Brasileira de Zootecnia, v.27, n.6, p.12061211, 1998.

HENRIQUE, W.; SAMPAIO, A.A.M.; LEME, P.R. et al. Desempenho e características da carcaça de tourinhos Santa Gertrudes confinados, recebendo dietas com alto concentrado e níveis crescentes de polpa cítrica peletizada. Revista Brasileira de Zootecnia, v.33, p.463-470, 2004.

HOPKINS, D.L.; FOGARTY, N.M. Diverse lamb genotypes. 2. Meat $\mathrm{pH}$, color and tenderness. Meat Science, v.49, n.4, p.477-488, 1998.

LAWRIE, R.A. Ciência da carne. 6.ed. Porto Alegre: Artmed, 2005. 384p.

LOFGREEN, G.P. The estimation of total digestible nutrients from digestible organic matter. Journal of Animal Science, v.12, p.359-365, 1953.

LYNCH, P.B.; KERRY, J.P. Utilizing diets to incorporate bioactive compounds and improve the nutritional quality of muscle foods. In: DECKER, E.; FAUSTMAN, C.; LOPEZ-BOTE, C. (Eds.). Antioxidants in muscle foods. New York: John Wiley, 2000, 512p.

NAKAMURA, M.; KATOH, K. Influence of thawing method on several properties of rabbit meat. Bulletin of Ishikawa Prefecture College of Agriculture, v.11, p.45-49, 1985.

NOTTER, D.R.; GREINER, S.P.; WAHLBERG, M.L. Growth and carcass characteristics of lambs sired by Dorper and Dorset rams. Journal of Animal Science, v.82, p.1323-1328, 2004.

NATIONAL RESEARCH COUNCIL - NRC. Nutrient requirements of dairy cattle. 7.ed. Washington, D.C.: National Academy Press, 2001. 381p

OLFAZ, M.; OCAK, N.; ERENER, G. et al. Growth, carcass and meat characteristics of Karayaka growing rams fed sugar beet pulp, partially substituting for grass hay as forage. Meat Science, v.70, p.7-14, 2005.
OLIVEIRA, M.V.M.; PÉREZ, J.R.O.; ALVES, E.L. et al. Rendimento de carcaça, mensurações e peso de cortes comerciais de cordeiros Santa Inês e Bergamácia alimentados com dejetos de suínos em confinamento. Revista Brasileira de Zootecnia, v.31, n.3, p.1451-1458, 2002.

RODRIGUES, G.H.; SUSIN, I.; PIRES, A.V. et al. Substituição do milho por polpa cítrica em rações com alta proporção de concentrado para cordeiros confinados. Ciência Rural, v.38, n.3, p.789-794, 2008.

SAÑUDO, C.; SANCHES, A.; AFONSO, M. Small ruminants production systems and factors affecting lamb meat quality. Meat Science, v.49, n.1, p.29-64, 1998

SANTOS-SILVA, J.; MENDES, I.A.; BESSA, R.J.B. The effect of genotype, feeding system and slaughter weight on the quality of light lambs. 1. Growth, carcass composition and meat quality. Livestock Production Science, v.76, p.17-25, 2002.

STATISTICAL ANALYSIS SYSTEM - SAS. System for Microsoft Windows. Release 8.0. Cary: 1999. (CD-ROM).

SCERRA, V.; CAPARRA, P.; FOTI, F. et al. Citrus pulp and wheat straw silage as an ingredient in lambs diets: effects on growth and carcass and meat quality. Small Ruminant Research, v.40, p.51-56, 2001.

SOUZA, X.R.; BRESSAN, M.C.; PÉREZ, J.R.O. et al. Efeitos do grupo genético, sexo e peso ao abate sobre as propriedades físico-químicas da carne de cordeiros em crescimento. Ciência e Tecnologia de Alimentos, v.24, n.4, p.543-549, 2004.

URANO, F.S.; PIRES, A.V.; SUSIN, I. et al. Desempenho e características da carcaça de cordeiros confinados alimentados com grãos de soja. Pesquisa Agropecuária Brasileira, v.41, n.10, p.1525-1530, 2006.

Van SOEST, P.J. Nutritional ecology of the ruminant. Corvallis: O\& Books, 1982. 373p.

VASTA, V.; NUDA, A.; CANNAS, A. et al. [2007]. Alternative feed resources and their effects on the quality of meat and milk from small ruminants. Disponível em: <http://dx.doi.org/ 10.1016/j.anifeedsci.2007.09.020> Acesso em: 15/1/2008.

ZAPATA, J.F.F.; SEABRA, L.M.J.; NOGUEIRA, C.M. et al. Estudo da qualidade da carne ovina no Nordeste brasileiro: propriedades físicas e sensoriais. Ciência e Tecnologia de Alimentos, v.20, n.2, p.274-277, 2000.

ZEOLA, N.M.B.L.; SILVA SOBRINHO, A.G.; GONZAGA NETO, S. et al. Influência da alimentação nas características quantitativas da carcaça e qualitativas da carne de cordeiros Morada Nova. Revista Portuguesa de Ciências Veterinárias, v.97, n.544, p.175-180, 2002. 